\title{
Tropical Cyclones and Perennial Species in the Mariana Islands
}

\author{
Thomas E. Marler \\ College of Agriculture and Life Sciences, University of Guam, UOG Station, Mangilao, Guam 96923
}

\section{TROPICAL CYCLONES AND ISLANDS}

The Mariana Islands belong to an expansive group of islands dubbed Micronesia. As this name implies, the typical island in Micronesia is relatively small. When the path of a tropical cyclone (TC) targets a Micronesian island, the small land area exerts little influence on the TC's intensity. In contrast, when a TC makes landfall on a continental coastline, the TC loses intensity fairly quickly because of the large land mass. This phenomenon affects the extent of damage to vegetation on an island and is of greater concern with slowly moving TCs. The slowly moving TC imposes damaging winds for extended periods without the accompanying decrease in intensity that might occur with a large land mass.

Perennial crops in the Mariana Islands are subjected to a high risk of being damaged by a TC. In fact, the most active TC basin in the world is the western North Pacific (Guard et al., 1999). No other state or territory of the United States is at a higher risk of being impacted by a TC than is the island of Guam, the largest of the Mariana Islands (Guard et al., 1999). Seventy-one TCs passed within $139 \mathrm{~km}$ of Guam during the period 1945-97.

\section{TYPES OF DAMAGE}

Perennial trees and shrubs experience varied forms of damage during the passage of a TC. Following are a few of the most common forms observed for perennial crops in the Mariana Islands.

Defoliation is the most common damage caused by TCs. Some species are easily defoliated, and even mild TCs remove their leaves. Starfruit (Averrhoa carambola L.) and mulberry (Morus L. sp.) are two fruit species that are easily defoliated. A benefit of defoliation is the consequent reduction in drag force of the wind. Thus, trees of these species are generally not uprooted during TCs, and many respond to defoliation with a condensed flowering period as regrowth occurs.

Breakage of small to medium-sized stems occurs on other species during TCs, including breadfruit [Artocarpus altilis (Parkins.) Fosb.]. Greater wind speeds are required to damage trees of these species than of species that are easily defoliated, but the cost of repairing the damage is also greater after loss of the structural tissue. Moreover, this type of damage introduces numerous structural wounds that are difficult for a woody perennial plant to seal over. This form of damage also reduces drag force of the wind, such that trees are not typically uprooted during TCs.

Physical trauma from airborne debris leads to structural damage of trees in many sites. The damaging debris may come from within the orchard, or from areas adjacent to the orchard. Moreover, anthropogenic debris becomes troublesome in many orchards where nearby construction materials have become airborne.

Snapping of the trunk near the soil and uprooting are the two most severe forms of damage during TCs. Uprooting occurs when the rootsoil plate fails to maintain anchorage for a tree. Failure of the root-soil plate typically precedes the point at which the wind force becomes great enough to snap trees in the Mariana Islands, so snapping is a rare form of damage in these islands. Numerous canopy and root characteristics interact to determine if a tree is vulnerable to being uprooted.

Received for publication 26 May 2000. Accepted for publication 20 June 2000. The cost of publishing this paper was defrayed in part by the payment of page charges. Under postal regulations, this paper therefore must be hereby marked advertisement solely to indicate this fact.

${ }^{1}$ E-mail address: tmarler@uog9.uog.edu

\section{FACTORS AFFECTING UPROOTING}

Most woody perennial plants recover fairly rapidly following TC damage, provided that they remain well-rooted and the major scaffold system of the canopy remains intact. Thus, horticulturists would benefit from understanding canopy and root characteristics involved in tree stability.

\section{Root anchorage}

Various methods have been adopted to determine the role of the components of root anchorage (Coutts, 1983, 1986; Ennos et al., 1993). Most plant anchorage is afforded by windward roots that act as "guy ropes." Greater root-to-soil contact on the windward side is critical for resisting uprooting, and this is manifested by a greater root surface area per unit volume of soil. Thus, a highly branched root architecture is important. Also of importance for resisting uprooting are roots on the downwind side of the canopy. Greater capacity to resist bending when these roots are placed under compression increases resistance to uprooting. Large structural roots are more resistant to bending, so relative root size is more important on the downwind side than is root-to-soil contact. A third factor in resisting uprooting is the combined weight of the soil, water, and roots within the plate levered from the ground as the canopy is displaced. Shear strength of the soil at the position where the soil plate breaks is also of importance, as are taproot characteristics in young trees.

Some of these root factors are under horticultural control. For example, substrate that allows greater vertical and lateral root growth will generally improve anchorage components, especially the total root-to-soil contact and the weight of the levered plate. Northern Guam is a limestone plateau over which a shallow layer of soil has formed. Rooting depth in these soils is greatly improved by mechanically breaking up the consolidated limestone, a commercial practice in southern Florida (Crane et al., 2000). Rooting depth in the acidic soils of southern Guam is minimal because of calcium deficiency and aluminum toxicity in the subsoil. Thus, amending with limestone is critical for improved root growth and increased resistance to uprooting.

\section{Canopy}

The force applied to a tree by wind depends on canopy size, shape, and characteristics (Cannell and Coutts, 1988; Kerzenmacher and Gardiner, 1998). The two-dimensional area of the canopy perpendicular to wind direction determines the maximum area that will be impacted. However, total canopy weight, leaf area density, leaf shape, flexibility of leaves and stems, which can reduce drag by bending, and the shedding of leaves or lateral branches as wind speed increases are other important characteristics that determine the drag force of wind.

For managed tree canopies, these characteristics are affected by horticultural practices. The two-dimensional area of the canopy is controlled by choice of species, and by the extent of heading-back cuts in routine pruning practices. The flow-through of wind is influenced by the extent of thinning-out cuts in pruning practices.

Epiphytes may be widespread in natural systems and minimally managed agroforestry systems of the Mariana Islands. Two of the most common large epiphytes are Ficus tinctoria var. neo-ebudarum (Summerh.) Fosb. and Polypodium punctatum (L.) Swartz. (Marler and Hirsh, 1998). Presence of epiphytes may influence several of the previously mentioned canopy characteristics, especially canopy area or weight, and thereby increase susceptibility to uprooting. Frangi and Lugo (1991) reported that the presence of epiphytes in sierra palm 
[Prestoea montana (R. Grah.) Nichols] in a Puerto Rican forest increased the likelihood of being uprooted during Hurricane Hugo

\section{Exposure to noncatastrophic winds}

Some canopy and root characteristics that determine susceptibility to uprooting are positively influenced by exposure to noncatastrophic winds during growth. For example, chronic trade winds limit the size of individual tree canopies, thus reducing canopy drag. Moreover, roots and major scaffold limbs are strengthened by exposure of the canopy to chronic winds. For example, anchorage tests were used to determine the force needed for a 3-cm lateral displacement of the stem of 'Red Lady' papaya (Carica papaya L.) plants after 4 months of growth on the windward vs. leeward sides of a windbreak. Anchorage strength of plants exposed to wind was $180 \pm 18 \mathrm{Nm}$, while that of plants protected from wind was $110 \pm 16 \mathrm{Nm}$ (Marler, unpublished data). Similarly, canopy wind exposure altered rooting characteristics of forestry species such that anchorage was improved (Stokes, 1999; Stokes et al., 1995). Foster (1988) reported that trees growing in exposed sites were more resistant to damage by catastrophic winds than were trees growing in protected areas.

\section{RESETTING UPROOTED TREES}

The previously described root and canopy characteristics apply to both natural and managed systems. In managed systems, however, horticulturists may also reset trees following uprooting by a TC. The decision to reset a tree is based primarily on tree value and extent of damage. A third factor that is less often considered is the biological factor of how well individuals of a species recover following resetting. Some species recover rapidly if reset properly. A popular ornamental tree in the Mariana Islands is Cassia surattensis Burm.f., and specimens of this tree are among the most likely to be uprooted by a TC. However, when reset properly after being uprooted, these trees recover rapidly.

When considering uprooting and resetting, the most troublesome species are those that remain viable, but rarely or only sluggishly recover to full production potential. An example is atemoya (Annona cherimola Mill. x Annona squamosa L.). Following uprooting and resetting, atemoya trees rarely die under the environmental conditions of the Mariana Islands. However, the trees grow and produce poorly for years. Adding to a grower's frustration is the fact that increased efforts to minimize stress during recovery rarely have an appreciable impact. Thus, growers may spend more time and resources in attempting to nurture these trees back to full production than they would to bring a replanted orchard into production.

\section{CARBOHYDRATE RELATIONS}

One of the widely studied responses of forest systems to TCs is the immense flux of biomass from the canopy to the forest floor. Most of the attention has focused on the dynamics of the forest floor following this pulse of litter. For example, the extraordinary volume of litter deposits large quantities of nutrients (Frangi and Lugo, 1991; Harrington et al., 1997; Herbert et al., 1999; Lodge et al., 1991) and affects seedling establishment (Guzman-Grajales and Walker, 1991; VazquezYanes et al., 1990) or survival of established seedlings (You and Petty, 1991). A phenomenon that exerts such a profound influence on the forest floor probably exerts an accompanying profound influence on the source of the litter. Thus, a key component during recovery after TC damage is the carbohydrate status of the individual plant.

Plants that can regrow rapidly following a disturbance utilize stored carbon to help initiate the recovery process (Schier and Zasada, 1973). The ratio of photosynthetic tissue to respiratory tissue is lower for most woody perennials than for herbaceous plants. With the loss of leaves following a TC, this ratio is further reduced. Plants that are already close to respiratory debt prior to defoliation may require extended periods to recover from defoliation. Lugo and Scatena (1996) reported that tree mortality may continue for years after TC damage, underscoring the need to more fully understand carbohydrate relations following TC damage.

\section{ABIOTIC INTERACTIONS}

The process of recovering from TC damage is influenced by many abiotic factors. Following are a few examples that influence speed of recovery of perennial crops in the Mariana Islands.

\section{Iron relations}

Some species that are predisposed to iron chlorosis exhibit increased leaf chlorosis following a TC. Increased frequency of $\mathrm{Fe}$ chelate drench applications can partially, but not completely, correct the chlorosis. The problem is more persistent in calcareous soils.

A likely cause of this response is reduced root growth following defoliation. Loss of foliage or any other occurrence that reduces carbon fixation inhibits formation of feeder roots (Vogt and Bloomfield, 1991), and reduced root growth following TC damage has been reported for a number of species (Herbert et al., 1999; Parrotta and Lodge, 1991; Silver and Vogt, 1993). Reduced root growth may in turn lead to reduced activity of $\mathrm{Fe}$ (III) reductase and the temporary increase in chlorosis that is common following TCs. Evidence for this is provided by several studies using papaya as a model. Root response to defoliation of papaya plants is rapid, with growing root tips completely disappearing within 1 week after complete defoliation (Marler and Stushnoff, 1999). The greatest $\mathrm{Fe}(\mathrm{III})$ reduction in papaya roots occurs 0-10 $\mathrm{mm}$ from the growing root tip (Fig. 1). Considering that root extension rate may be $>10 \mathrm{~mm} \cdot \mathrm{d}^{-1}$ (Nakasone and Paull, 1998), any decrease in root extension would compromise the ability of a papaya plant to mine the soil. Thus, the loss of growing root tips following defoliation will directly reduce the Fe(III) reduction potential for a papaya plant.

Leaves exhibiting iron chlorosis are susceptible to exposure to excessive light. For a range of species, effective PSII quantum effi-

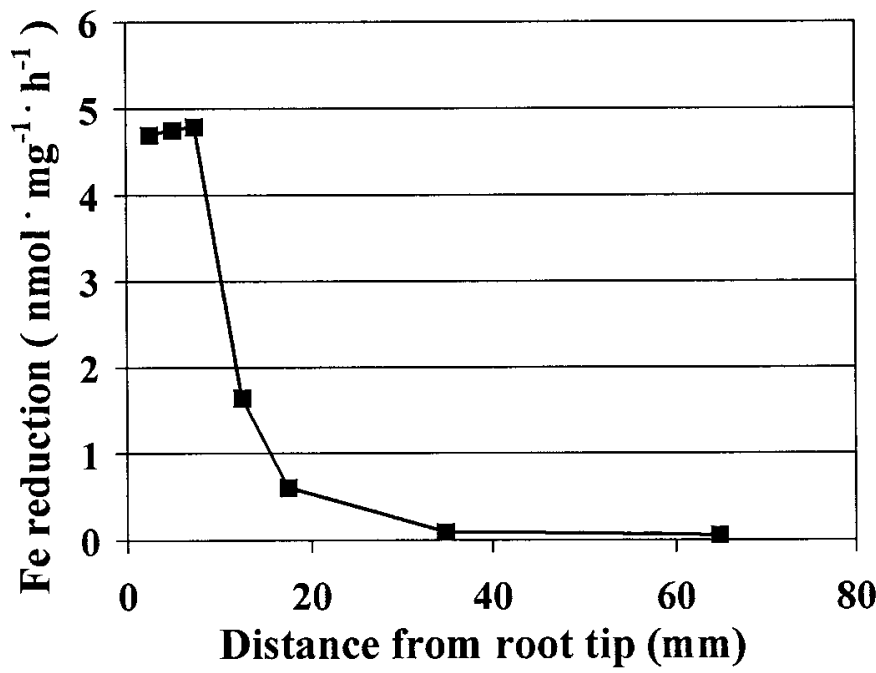

Fig. 1. The influence of distance from root tip on ferric reduction of 'Sunrise' papaya roots. Plants were grown in an aeroponic system and the nutrient solution was devoid of iron for $19 \mathrm{~d}$ prior to the assay $(n=6)$ (Marler, unpublished data).

Table 1. Effective PSII quantum efficiency ${ }^{2}$ of atemoya, calamondin (X Citrofortunella mitis J. Ingram \& H.E. Moore), Surinam cherry (Eugenia uniflora L.), hibiscus (Hibiscus rosa-sinensis L.), and ixora (Ixora coccinea L.) leaves actively engaged in photosynthesis under ambient light conditions on 16 May 1998.

\begin{tabular}{llcc}
\hline \hline Species & Family & Green leaves & Leaves with iron chlorosis \\
\hline Atemoya & Annonaceae & $0.245 \pm 0.005$ & $0.136 \pm 0.004$ \\
Calamondin & Rutaceae & $0.219 \pm 0.013$ & $0.107 \pm 0.007$ \\
Surinam cherry & Myrtaceae & $0.233 \pm 0.006$ & $0.064 \pm 0.007$ \\
Hibiscus & Malvaceae & $0.207 \pm 0.006$ & $0.119 \pm 0.015$ \\
Ixora & Rubiaceae & $0.212 \pm 0.018$ & $0.141 \pm 0.009$
\end{tabular}

${ }^{2}$ Mean photosynthetic photon flux during measurements was $1406 \mu \mathrm{mol} \cdot \mathrm{m}^{-2} \cdot \mathrm{s}^{-1}$. $\mathrm{n}=10$. (Marler, unpublished data).

'The iron chlorosis was a result of damage by Typhoon Paka in Dec. 1997. 
ciency of leaves actively engaged in photosynthesis under ambient light conditions is reduced by TC-induced iron chlorosis (Table 1). Thus, the previously described phenomena may be integrated into an explanation of one facet of TC damage. Defoliation, a form of direct TC damage, reduces root growth, which in turn reduces $\mathrm{Fe}(\mathrm{III})$ reduction potential, leading to iron chlorosis, and thus to reduced effective PSII quantum efficiency.

\section{Post-TC exposure of tissue}

Defoliation of the outermost portion of a tree may lead to exposure of understory leaves or woody tissues to direct sunlight. Newly exposed, intact leaves may be damaged by the increased light load or newly exposed woody tissues may be damaged by heat stress. Mango (Mangifera indica L.) stems are particularly susceptible to heat damage following defoliation by a TC.

Agroforestry systems are common throughout the Pacific islands, and are typically comprised of multiple canopy layers. Loss of foliage within the uppermost layer commonly occurs during TCs, and exposes the lower layers to more intense sunlight. Evidence that this can be damaging to the newly exposed shade leaves is provided in experiments using Cycas micronesica K.D. Hill as a model. Following removal of shade, maximum and effective quantum efficiency of PSII declined within $1 \mathrm{~d}$ (Fig. 2). A result of the high light stress was a reduction in midday net $\mathrm{CO}_{2}$ assimilation $\left(\mathrm{A}_{\mathrm{CO} 2}\right)$. Shade-grown leaves exhibited midday $\mathrm{A}_{\mathrm{CO} 2}$ of $\approx 8 \mu \mathrm{mol} \cdot \mathrm{m}^{-2} \cdot \mathrm{s}^{-1}$ prior to removal of shade; following 2 weeks in full sun conditions their midday $\mathrm{A}_{\mathrm{CO} 2}$ was $\approx 2.5$ $\mu \mathrm{mol} \cdot \mathrm{m}^{-2} \cdot \mathrm{s}^{-1}$ (Marler, unpublished data).

\section{Salt spray}

Aerosol deposits of salt are associated with coastal regions. Thus, when growing perennial crops on small islands, there is no escape from the possibility of salt problems following a TC. The typical TC brings abundant rainfall, which removes any aerosol salt deposits. However, osmotic desiccation of leaves and herbaceous tissue following a TC that carries limited rainfall is highly likely on any island.

\section{Post-TC wind exposure}

Trade winds inhibit growth and productivity of horticultural crops on Guam, where sustained winds of $7-11 \mathrm{~m} \cdot \mathrm{s}^{-1}$ are common (Singh et al., 1994). Two woody perennial windbreak species used in horticultural systems in the Mariana Islands are acacia (Acacia auriculiformis A. Cunn. ex Benth.) and ironwood (Casuarina equisetifolia J.R. Forst.

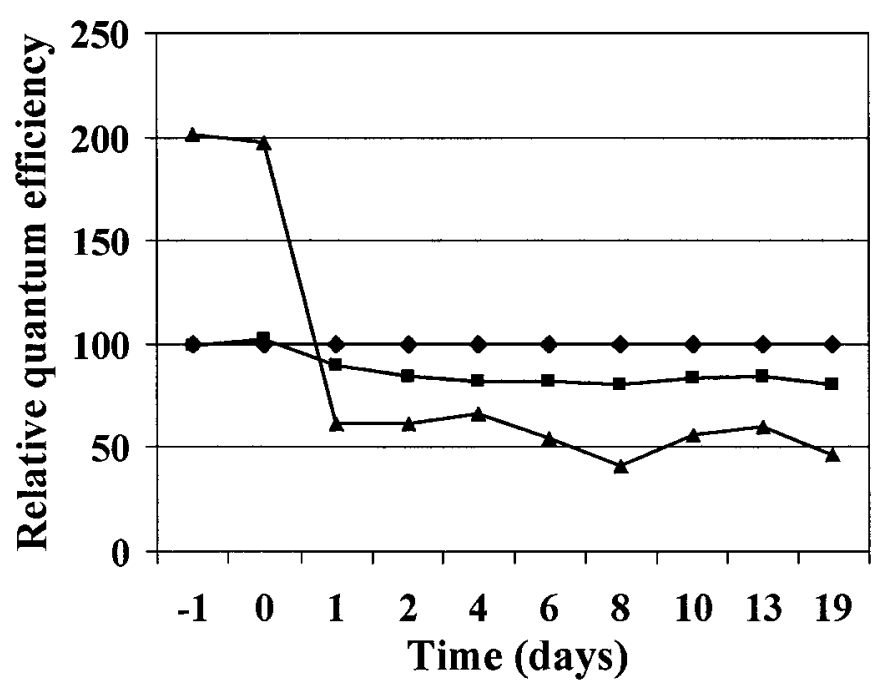

Fig. 2. The influence of loss of shade cover (day 0 ) on maximum quantum efficiency of PSII photochemistry measured at night (ם), and effective quantum efficiency of PSII measured at midday $(\mathbf{A})$ of Cycas micronesica leaves grown in $35 \%$ sunlight. Data are presented as percentages of values relative to full-sun leaves $(\bullet)$ (Marler, unpublished data).
$\&$ G. Forst.). Both are highly effective for wind protection, especially when used in combination. The acacia windbreaks are susceptible to major structural damage during a TC, but the ironwood windbreaks are less susceptible. Thus, planting acacia windbreaks increases the likelihood of a temporary loss of crop protection following a destructive TC.

\section{BIOLOGICAL INTERACTIONS}

When a TC impacts the urban landscape or commercial orchard, horticultural specimens are not the only biological organisms that are influenced by the TC. Following are examples of how these organisms influence recovery of horticultural crops in the Mariana Islands.

Several frangipani (Plumeria L. ) species are widely planted in the urban landscape on Guam. A rust (Coleosporium plumeriae Pat.) was recently introduced to the island, and has subsequently become possibly the greatest horticultural problem associated with growing frangipani plants. Particularly acute outbreaks of the rust appear during the weeks following the wet, windy conditions of a mild TC, one that is not strong enough to uproot or fully defoliate the plants.

Papaya is one of the most widely planted fruit species in the Mariana Islands. A chronic but rarely epidemic disease is caused by the bacterium Erwinia. Symptoms include rapidly advancing chlorosis and necrosis of older leaves. Immature or mature fruits develop wet, dark spots that increase in size and coalesce. Mesocarp discoloration usually exceeds that of the surface discoloration. A combination of mild TC damage and subsequent rainy weather typically generates an outbreak of the disease in less than 2 weeks, either by increasing inoculum dispersal or by improving environmental conditions for the bacterium. Diligent scouting for the highly likely outbreak following the passage of a TC, and rapid removal of symptomatic tissue, are required to prevent a major outbreak of the disease.

Some of the biological interactions following a TC may be beneficial for horticulturists. For example, papaya ringspot virus (PRV) remains the most severe, chronic problem for papaya production in the Mariana Islands. Several aphids efficiently transmit PRV from infected to healthy plants. The incidence of PRV in orchards sometimes declines for extended periods following a TC. A change in the relative volume of inoculum external to orchards or a change in the population of efficient aphid vectors are possible causes of this reduction in PRV pressure. Aphid populations on Guam returned within 2 weeks following Typhoon Keith (1 Nov. 1997) and Typhoon Paka (16-17 Dec. 1997) (R.H. Miller, personal communication). This rapid return is evidence that the relative volume of inoculum is probably responsible for the temporary decline in PRV incidence following many TCs. Papaya has naturalized on Guam, and diseased plants in unmanaged areas are a widespread source of PRV inoculum. Because of the herbaceous growth habit of this giant herb, damage to the naturalized population is severe during a typical TC. The result is an economic benefit for growers who take steps to return to full production rapidly after a TC.

Other beneficial examples of a TC include the temporary decline in populations of several fruit-piercing moth species. Following Typhoon Paka in Dec. 1997, temporary relief from attacks by moths allowed the substantial urban forest population of royal poinciana (Delonix regia Bojer) trees to display copious flower production in the summer of 1998. Soft fruits that are susceptible to fruit-piercing moth damage, such as purple mombin (Spondias purpurea L.), starfruit, and guava (Psidium guajava L.), were less damaged by adult moths in 1998 than in many previous years.

\section{ANTHROPOGENIC INTERACTIONS}

The biological interaction exerting possibly the greatest influence on damage and recovery of horticultural specimens from TCs is the interaction between perennial plants and humans. The consequences of poor management practices may be minimal in climates that are characterized by few large-scale disturbances, but in the Mariana Islands their consequences are considerable.

Bark damage at the base of tree trunks is common in the Mariana Islands because of the use of string weed trimmers. This chronic damage leads to reduced root vigor and compromises anchorage 
characteristics. Severe heading-back of trees is also a common practice. These poor pruning practices produce regrowth with increased canopy drag characteristics, thereby increasing susceptibility to TC damage.

The precipitation associated with a TC is typically many times that of background rainfall. For example, about $50 \mathrm{~cm}$ of rain was associated with the passage of Typhoon Paka in Dec. 1997 (Marler and Hirsh, 1998). In the Mariana Islands, the probability of experiencing highintensity rainfall events should be considered prior to conducting any horticultural practice that increases susceptibility of property to erosion. Land clearing and cultivation practices should be restricted to the few months immediately after the annual TC season to ensure recovery of vegetation before the next season.

Land clearing also increases susceptibility of some retained trees to TC damage. Breadfruit and yoga (Elaeocarpus joga E.D. Merrill) are two common trees in the Mariana Islands, and specimens of both species are severely damaged by a TC event if land-clearing around them occurs prior to its passage.

\section{SEQUENTIAL DISTURBANCES}

Recovery from TC damage occurs most rapidly in the absence of stress. Thus, exposure to a second disturbance may have a strong influence on recovery.

Typhoon Paka passed by Guam in Dec. 1997. As the rains associated with the TC subsided, a near record dry year began. All TCs that occur late in the season carry with them this risk, as the annual dry season alternates with the most active TC season. The dry weather and typhoon debris fueled forest and grassland fires that consumed $12 \%$ of the island during 1998 (Lander, 2001). Fires are fairly common in naturalized areas on Guam, but trees experienced more damage during these 1998 fires than in typical fires. This may be because the trees were more stressed following the $\mathrm{TC}$ or because the increase in debris fueled more damaging fires. Mortality in a Samoan forest following Tropical Cyclone Ofa was $\approx 28 \%$, but in one area subjected to the TC and a subsequent fire, mortality was 91\% (Elmqvist et al., 1994). Similarly, an extensive fire in northeastern Yucatan Peninsula forests followed Hurricane Gilbert, and damage by the fire was greater than that caused by the hurricane itself (Whigham et al., 1991).

The University of Guam maintains several sites for evaluation of fruit germplasm. One of these sites lacks irrigation. Mortality among all species on this site was $\approx 40 \%$ by the end of Summer 1998 because of combined effects of the Dec. 1997 TC and the subsequent severe drought. That the combination of effects was causal is evidenced by the minimal mortality on the two irrigated germplasm sites that experienced similar TC damage.

Herbert et al. (1999) reported widespread defoliation by several high wind events that followed the passage of Hurricane Iniki on Kauai, Hawaii. This was attributed to reduced force required for leaf removal of the regrown foliage after the hurricane.

\section{TIMING OF TROPICAL CYCLONE}

The timing of summer pruning is critical in determining subsequent growth responses. Similarly, the timing of TC damage is an important factor influencing the recovery of perennial crops. As previously mentioned, late-season TCs in the Mariana Islands carry with them a high risk of subsequent drought stress. In contrast, early season TCs are normally followed by abundant rains during the initial few months of recovery.

The phenology of a perennial species will determine the level of importance that timing of a TC exerts on subsequent recovery. For example, purple mombin trees are rarely structurally damaged by TCs because they are defoliated in the early stages of the storm. Vegetative recovery is rapid regardless of timing, but the reproductive growth responses following a TC are directly influenced by timing. This species is deciduous, and short photoperiods trigger natural defoliation. Since the photoperiod cues are not very strong in the Mariana Islands, defoliation during the season of short days is usually only partial for most genotypes. Flowering and fruiting are minimal or modest in a normal year. However, yields were higher in 1998 than in any year in recent history as a result of complete defoliation by Typhoon Paka in Dec. 1997, the time when the trees should have been dropping leaves. In contrast, the passage of a TC during the summer or early fall usually triggers excessive vegetative regrowth responses because this coincides with the optimal photoperiod for vegetative growth. This excessive growth reduces defoliation when photoperiods shorten, and hence flowering the following year. Thus, the timing of the TC determines whether fruit production will be enhanced or reduced in this species.

Cannell and Coutts (1988) report that windstorms in Britain are more damaging to deciduous tree species in summer than in winter. During winter these trees are leafless and offer less wind drag than they do during the growing season.

\section{MANAGED AND NATURAL SYSTEMS}

\section{Relevance of the literature}

The literature covering plant recovery from TC damage is fairly extensive. However, the preponderance of data comes from natural landscapes, not managed landscapes. The relevance of this literature to horticulture depends on the application; many of the conclusions drawn may have minimal application to horticultural systems.

- Claims of rapid recovery of system components are based on recovery to pre-TC levels in 5-10 years (Fu et al., 1996; Zimmermann et al., 1996). This may be rapid on an ecological scale; however, a horticulturist's livelihood depends on a marketable product. As little as 1 year out of production can be disastrous.

- Natural systems are a complex mosaic of vegetation, and loss of function of one component of that mosaic may be partially or fully compensated for by other components. In contrast, most horticultural systems are monocultures, and recovery following damage rests solely on the single species.

In contrast with these examples, some of the principles developed within the ecology literature may provide insights for management of orchard recovery following a TC.

- Following TC damage to an Australian forest, several vine species appeared in abundance (Webb, 1958). The ecological relevance of this observation relates to recruitment and population dynamics. The horticultural relevance is that exotic weeds may become more of a management problem in an orchard following a TC.

- The loss of fine roots in the forest floor (Herbert et al., 1999; Parrotta and Lodge, 1991; Silver and Vogt, 1993) has been studied in the context of ecosystem development and function. Roots may require more than 1 year to recover to pre-TC levels (Parrotta and Lodge, 1991). Considering the complex interrelationships among fruit, vegetative, and root growth, the knowledge that root growth is compromised for lengthy periods following TC damage may be of use to horticulturists in making management decisions for orchard recovery.

- Schowalter(1994) reported that invertebrates responded to changes in a natural forest brought about by Hurricane Hugo. The types of invertebrate herbivores present increased because of an increase in types of micro-sites generated by the TC. The horticultural relevance is that TC damage may increase the abundance and types of herbivores in orchards. Indeed, Campbell et al. (1993) reported increased woodboring and root-feeding weevils in southern Florida orchards following Hurricane Andrew.

- Lodge et al. (1991) reported that almost $50 \%$ of the debris generated by Hurricane Hugo remained suspended in the broken tree canopies of a Puerto Rican forest for as long as 1 year. The ecological relevance is that suspended debris can affect nutrient cycling. The horticultural significance of this report is the daunting volume of labor needed for cleaning up broken canopies and removing debris from an orchard following a TC.

\section{Voids in the literature}

Horticulturists are in a position to fill voids in the current body of knowledge regarding plant recovery from TC damage. 
- The response variables most commonly reported in the ecological literature are vegetative or ecosystem variables. Some of these include leaf area index, diameter at breast height, mineral cycling, and recruitment characteristics. Fruit scientists are interested in timing, quality, and quantity of fruit production. Reports on recovery of reproductive capacity following TC damage are conspicuously missing from the ecological literature.

- Several reports in the ecological literature were based on experimental plots from which growth data were available prior to the direct passage of a TC (Frangi and Lugo, 1991; Harrington et al., 1997; Herbert et al., 1999; Silver and Vogt, 1993). Other studies employed retrospective analysis, looking primarily at growth rings of individual plants to determine their history (Foster, 1988; Merrens and Peart, 1992). Aside from these publications, the vast majority of the literature is comprised of reports based on natural systems about which little was known prior to the TC. Formal or informal management records are relatively extensive in horticulture. Following the passage of a TC, horticulturists are in the enviable position of being able to combine the data on post-TC recovery processes with extensive pre-TC records.

\section{Literature Cited}

Campbell, R.J., C.W. Campbell, J. Crane, C. Balerdi, and S. Goldweber. 1993. Hurricane Andrew damages tropical fruit crops in South Florida. Fruit Var. J. 47:218-225.

Cannell, M. and M. Coutts. 1988. Growing in the wind. New Scientist 117:4246.

Coutts, M.P. 1983. Root architecture and tree stability. Plant Soil 71:171-188.

Coutts, M.P. 1986. Components of tree stability in Sitka spruce on peaty, gley soil. Forestry 59:173-197.

Crane, J.H., B. Schaffer, and R.J. Campbell. 2001. Recovery from hurricanes and the long-term impacts on perennial tropical fruit crops in South Florida. HortScience 36:258-263.

Elmqvist, T., W.E. Rainey, E.D. Pierson, and P.A. Cox. 1994. Effects of tropical cyclones Ofa and Val on the structure of a Samoan lowland rain forest. Biotropica 26:384-391.

Ennos, A.R., M.J. Crook, and C. Grimshaw. 1993. A comparative study of the anchorage systems of Himalayan balsam Impatiens glandulifera and mature sunflower Helianthus annuus. J. Expt. Bot. 44:133-146.

Foster, D.R. 1988. Species and stand response to catastrophic wind in central New England, USA. J. Ecol. 76:135-151.

Frangi, J.L. and A.E. Lugo. 1991. Hurricane damage to a flood plain forest in the Luquillo mountains of Puerto Rico. Biotropica 23:324-335.

Fu, S., C.R. Pedraza, and A.E. Lugo. 1996. A twelve-year comparison of stand changes in a mahogany plantation and a paired natural forest of similar age. Biotropica 28:515-524.

Guard, C.P., M.P. Hamnett, C.J. Neumann, M.A. Lander, and H.G. Siegrist, Jr. 1999. Typhoon vulnerability study for Guam. WERI Tech. Rpt. 85. Water and Environmental Res. Inst. Western Pacific. Univ. Guam, Mangilao.

Guzman-Grajales, S.M. and L.R. Walker. 1991. Differential seedling responses to litter after hurricane Hugo in the Luquillo experimental forest, Puerto Rico. Biotropica 23:407-413.

Harrington, R.A., J.H. Fownes, P.G. Snowcroft, and C.S. Vann. 1997. Impact of Hurricane Iniki on native Hawaiian Acacia koa forests: Damage and two- year recovery. J. Trop. Ecol. 13:539-558.

Herbert, D.A., J.H. Fownes, and P.M. Vitousek. 1999. Hurricane damage to a Hawaiian forest: Nutrient supply rate affects resistance and resilience. Ecology 80:908-920.

Kerzenmacher, T. and B. Gardiner. 1998. A mathematical model to describe the dynamic response of a spruce tree to the wind. Trees 12:385-394.

Lander, M.A. 2001. Tropical cyclones. HortScience 36:242-247.

Lodge, J.D., F.N. Scatena, C.E. Asbury, and M.J. Sanchez. 1991. Fine litterfall and related nutrient inputs resulting from hurricane Hugo in subtropical wet and lower montaine rain forests of Puerto Rico. Biotropica 23:336-342.

Lugo, A.E. and F.N. Scatena. 1996. Background and catastrophic tree mortality in tropical moist, set and rain forests. Biotropica 28:585-599.

Marler, T.E. and H. Hirsh. 1998. Guam's Cycas micronesica population ravaged by Supertyphoon Paka. HortScience 33:116-118.

Marler, T.E. and C. Stushnoff. 1999. Root, stem, and fruit growth of 'Tainung 1' papaya plants following defoliation. HortScience 34:488-489. (Abstr.)

Merrens, E.J. and D.R. Peart. 1992. Effects of hurricane damage on individual growth and stand structure in a hardwood forest in New Hampshire, USA. J. Ecol. 80:787-795.

Nakasone, H.Y. and R.E. Paull. 1998. Tropical fruits. CAB Intl., New York.

Parrotta, J.A. and D.J. Lodge. 1991. Fine root dynamics in a subtropical wet forest following hurricane disturbance in Puerto Rico. Biotropica 23:343347.

Schier, G.A. and J.C. Zasada. 1973. Role of carbohydrate reserves in the development of root suckers in Populus tremuloides. Can. J. For. Res. 3:243-250.

Schowalter, T.D. 1994. Invertebrate community structure and herbivory in a tropical rain forest canopy in Puerto Rico following Hurricane Hugo. Biotropica 26:312-319.

Silver, W.L. and K.A. Vogt. 1993. Fine root dynamics following single and multiple disturbances in a subtropical wet forest ecosystem. J. Ecol. 81:729-738.

Singh, P., T. Marler, and M. Marutani. 1994. Plant stress in Micronesia, p. 3. In: T.L. Davenport and H.M. Harrington (eds.). Proc. plant stress in the tropical environment. 20-25 Sept. 1992, Kailua-Kona, Hawaii.

Stokes, A. 1999. Strain distribution during anchorage failure of Pinus pinaster Ait. at different ages and tree growth response to wind-induced root movement. Plant Soil 217:17-27.

Stokes, A, A.H. Fitter, and M.P. Coutts. 1995. Responses of young trees to wind and shading: effects on root architecture. J. Expt. Bot. 46:1139-1146.

Vazquez-Yanes, C., A. Orozco-Segovia, E. Rincon, and M.E. SanchezCoronado. 1990. Light beneath the litter in a tropical forest: Effect on seed germination. Ecology 71:1952-1958.

Vogt, K.A. and J. Bloomfield. 1991. Tree root turnover and senescence, p. 287 306. In: Y. Waisel, A. Eshel, and U. Kafkafi (eds.). Plant roots-The hidden half. Marcel Dekker, New York.

Webb, J.L. 1958. Cyclones as an ecological factor in tropical lowland rainforest, North Queensland. Austral. J. Bot. 6:220-228.

Whigham, D.F., I. Olmsted, E.C. Cano, and M.E. Harmon. 1991. The impact of Hurricane Gilbert on trees, litterfall, and woody debris in a dry tropical forest in the northeastern Yucatan Peninsula. Biotropica 23:434-441.

You, C. and W.H. Petty. 1991. Effects of hurricane Hugo on Manilkara bidentata, a primary tree species in the Luquillo experimental forest of Puerto Rico. Biotropica 23:400-406.

Zimmerman, J.K., M.R. Willig, L.R. Walker, and W.L. Silver. 1996. Introduction: Disturbance and Caribbean ecosystems. Biotropica 28:414-423. 